\title{
The Effects of Oxytocin on Withdrawal, Craving and Stress Response in Heroin-Dependent Patients: A Randomized, Double-Blind Clinical Trial
}

\author{
Mina Moeini ${ }^{a, b}$ Abdoallah Omidia, c Mojtaba Sehat ${ }^{d} \quad$ Hamid Reza Banafshe $^{a, b, e}$ \\ a Department of Addiction Studies, School of Medicine, Kashan University of Medical Sciences, Kashan, Iran; \\ ${ }^{b}$ Physiology Research Center, Kashan University of Medical Sciences, Kashan, Iran; ' Department of Clinical Psychology, \\ School of Medical, Kashan University of Medical Sciences, Kashan, Iran; ${ }^{\mathrm{d}}$ Department of Epidemiology, School of \\ Medicine, Kashan University of Medical Sciences, Kashan, Iran; ${ }^{e}$ Department of Pharmacology, School of Medicine, \\ Kashan University of Medical Sciences, Kashan, Iran
}

\section{Keywords}

Oxytocin · Heroin · Withdrawal · Craving $\cdot$ Cortisol

\begin{abstract}
Opioid dependence is an increasing clinical and public health problem. Current pharmacotherapies have limited efficacy and cause serious side effects. Increasing bodies of evidences suggest the neuropeptide, oxytocin (OT), as a potential treatment for drug abuse disorders. The current study was designed to evaluate the effect of OT on withdrawal, craving and anxiety scores, cortisol and dehydroepiandrosterone sulphate (DHEAS) blood level in heroin-dependent male patients. This randomized, double-blind placebo-controlled clinical trial was conducted on 58 males with opioid dependence by Abstinence Center of Addictive People in Iran. The participants were randomly allocated to receive intranasal OT (single dose; $40 \mathrm{IU}, n=29$ ) or placebo $(n=29)$. Heroine withdrawal, craving and anxiety scores were measured using the Opioid Withdrawal Scale, Visual Analogue Scale and (Desire for Drug Questionnaire), and Hamilton checklist respectively. The cortisol and DHEAS levels at baseline and different post-intervention time were measured using a competitive immunoanalysis method. Acute OT ad-
\end{abstract}

ministration reduced craving and withdrawal scores but did not change anxiety significantly. Single dose of OT decreased the level of cortisol and improved the cortisol/DHEAS ratio in the heroin users during abstinence $(p<0.01)$. These results suggest that OT may be useful in the attenuation of craving, withdrawal symptom in heroin-dependent patients and might be considered a new potential treatment for heroin dependence where positive effects of OT on stress-related hormones may be involved in this effect of OT.

(C) 2019 S. Karger AG, Basel

\section{Introduction}

About 31 million people worldwide are affected by drug use disorders. According to WHO, roughly 450,000 people died as a result of drug use in 2015. Opioids continued to cause the most harm, accounting for $76 \%$ of the deaths where drug use disorders were implicated. The recent increase of opium production has resulted in an increase in heroin use in many nations [1]. Heroin dependence is a devastating, chronic psychiatric disorder. It is a maladaptive state associated with a withdrawal syndrome and intense craving. Heroin dependents experi-

\section{KARGER}

(c) 2019 S. Karger AG, Basel

E-Mail karger@karger.com

www.karger.com/ear
Dr. Hamid Reza Banafshe

Department of Addiction Studies, School of Medicine

Kashan University of Medical Sciences

Kashan (Iran)

E-Mail banafshe-h@kums.ac.ir 
ence an extreme amount of stress for a long period of time after they stop drug abuse. Treatment strategies in drug dependence are usually aimed at achieving control of withdrawal syndromes and reducing relapse and craving. Several protocols of treatment are available for heroin dependence including both behavioural and pharmacological interventions [2]. Methadone maintenance therapy (MMT) has become a treatment of choice for chronic opioid-dependent patients who cannot achieve abstinence. It has been shown that MMT can reduce heroin use, risk of HIV transmission, mortality, and crime [3]. However, MMT have limited effectiveness for some patients due to a variety of pharmacological and individual factors, while long-term methadone use can cause damage to the nerves, liver and cardiovascular system. This has led to the development of alternative forms of maintenance treatments [4].

Oxytocin (OT) is a neuropeptide that is produced by the hypothalamus and plays an important role in reward, social affiliation and bonding, associative learning, memory and stress responses $[5,6]$. There is now strong evidence that $\mathrm{OT}$ is a possible candidate for the treatment of maladaptive processes associated with addiction [7]. OT inhibits opioid tolerance [8], reduces opiates self-administration and decreases craving and stress response in marijuana dependent individuals [9]. A negative relationship between plasma OT levels and novelty seeking and increased negative affect and stress in different types of drug abuse have also been demonstrated $[10,11]$. Abstinent heroin-dependent patients experience negative affective state characterized by dysphoria, irritability, anxiety, as well as abnormal stress reactivity that drives drug seeking behaviours. These patients show elevated stress reactivity during withdrawal syndrome, which is related to heightened craving and symptoms of withdrawal [12]. Indeed, the activation of the hypothalamic-pituitary-adrenocortical axis and the elevated cortisol levels have been reported during opioid withdrawal syndromes, while opioid agonist administration reduced cortisol secretion, craving scores and amygdala activity in heroindependent patients [13]. Furthermore, dehydroepiandrosterone sulphate (DHEAS) may buffer the effects of cortisol and play a role in the resilience and in successful adaptation to the stress. Cortisol and DHEAS and especially cortisol/DHEAS ratio are assaying as neuroadaptive stress hormones to predict health outcome $[14,15]$. Given the established strong link between stress, drug use and relapse as along with the known dysregulation of hypothalamic pituitary adrenal (HPA) axis activity associated with substance-use disorders [16], the effects of OT on the stress system have received a lot of attention. Therefore, the current study was designed to evaluate the acute effect of OT administration on withdrawal, craving, anxiety scores, and neuroadaptive stress hormones levels in the male heroin-dependent individuals.

\section{Methods}

\section{Trial Design and Participants}

This randomized, double-blind placebo-controlled clinical trial was registered in the Iranian website for registration of clinical trials as http://www.irct.ir: IRCT (2015103024792N1). This research was carried out in accordance with the Declaration of Helsinki and received approval from the Ethics Committee of Kashan University of Medical Sciences (KAUMS). The participants were recruited from an inpatient treatment centre of $(\mathrm{Be}-$ hzisti Addiction Rehabilitation Center, Isfahan, Iran), between December 2016 and March 2017. The participants (58 males) were selected by trained staff at the clinic following a blindness method. Due to the inadequacy of female heroin-dependent patients (only 4 ), the trial was carried out with only male patients referred to the centre. During a distinctive period of time (6-9 days from abstinence), the subjects were prevented from taking any kind of illicit drugs including narcotic medicines. Only those participants who met the DSM-IV criteria for heroin dependence were selected. The participants were 20-60 years old. Exclusion criteria included other current substance abuse or dependence along with use of any psychoactive medication or medication known to alter HPA axis function. Drug urine tests were carried out to ensure that the subjects remained drug-free during the experiment. The procedure was fully described for each subject before starting the project and written informed consent was obtained [17].

\section{Randomization}

The subjects were assigned randomly to the treatment condition via a computer-generated random number by the aid of a trained staff at the clinic blindly.

\section{Laboratory Procedures}

An indwelling catheter was inserted at least $3 \mathrm{~h}$ before the sampling at 7 a.m. on the test day. The first cortisol and DHEAS blood sample were collected at 10 a.m. and then heroine withdrawal symptom was measured using the Clinical Opioid Withdrawal Scale [18]. The craving scores were assessed by Visual Analogue Scale [19] and Desire for Drug Questionnaire [20], while the anxiety was evaluated by Hamilton checklist [21]. Basal cortisol and DHEAS levels were assessed using a competitive immunoanalysis method on the COBAS E411 device. Referent intervals for morning cortisol and DHEAS were 138-690 nmol/L and $3-11 \mu \mathrm{mol} / \mathrm{L}$ respectively. The participants were provided with a light lunch. Then, medication was provided by the manufacturer of intranasal OT spray purchased from Novartis, Switzerland and the placebo spray (normal saline) purchased from Raha Company, Iran. At 13:15 p.m., 40 IU of OT or normal saline
Eur Addict Res 2019;25:41-47 DOI: $10.1159 / 000496194$
Moeini/Omidi/Sehat/Banafshe 
Fig. 1. Summary of the patient flow diagram.

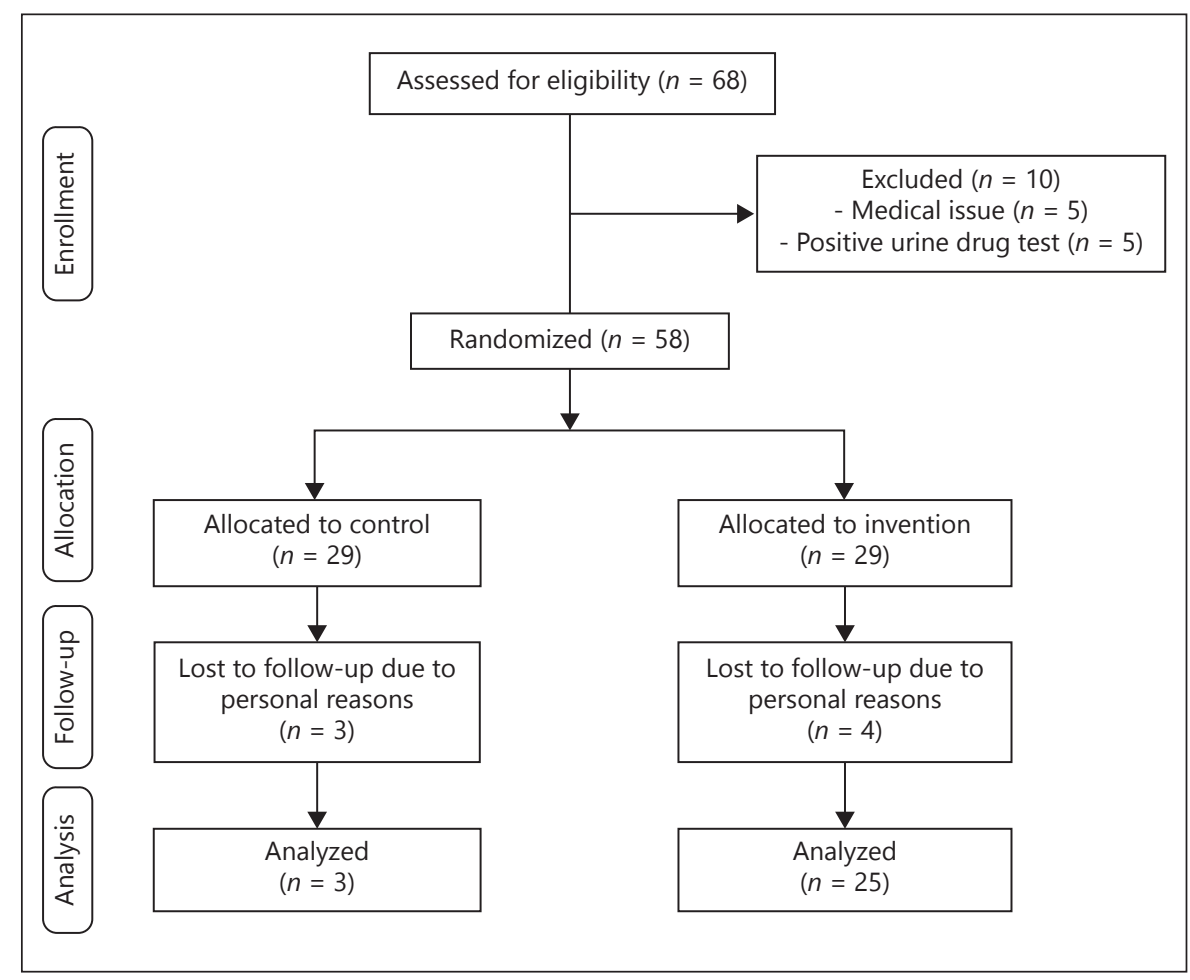

was administered intranasally according to the previous studies $[22,23]$. The participants were tested cue-induced craving task at 14 p.m. The task was a pictorial design consisted of heroin-related stimuli (heroine, pack, lighter, foil, heroine smoking, meeting a drug-using peer, watching others preparing and smoking) and neutral stimuli $[24,25]$. At 14:15 p.m., the task was completed. Withdrawal, craving and anxiety measurements were assessed again and then cortisol and DHEAS blood samples were collected from the participants at 30 and $60 \mathrm{~min}$ after the commencement of the task.

\section{Statistical Analysis}

To establish the normal distribution of the variables, the Kolmogorov-Smirnov test was used. The analyses were carried out based on the intention-to-treat protocol. Demographic, clinical and biological variables between the case and control groups were compared using the independent sample $t$ test and 1-way repeated measures analysis of variance respectively. Differences in the proportions were assessed by the chi square test. Data is presented as mean \pm SD or as median. The cortisol/DHEAS ratio was calculated as cortisol/DHEAS (*100).

\section{Results}

\section{Demographics}

A total of 68 individuals were interviewed and assessed for the study participation. The reasons for the study exclusion were medical issues $(n=5)$ and inability to pro- vide a negative urine drug screen $(n=5)$. Therefore, this clinical trial was conducted on 58 male heroine addicted patients allocated to receive intranasal OT (single dose; $40 \mathrm{IU}, n=29)$ or placebo $(n=29)$ randomly. During the treatment phase of the study, 4 patients from the control and 3 patients from the treatment groups could not complete the trail (Fig. 1). Finally, our analysis sample included 51 participants (OT $[n=27]$ and placebo $[n=24]$ ). The mean age of the participants was 33.8 years $(\mathrm{SD} \pm 8.8$ years). There were no significant differences between the 2 groups in terms of demographic information such as marital status and educational level (Table 1).

\section{The Effects of OT on Withdrawal, Craving and Anxiety Scores}

As shown in Table 2, intranasal administration of a single dose of OT significantly improved Desire for Drug Questionnaire $(-17.16 \pm 4.36$ vs. $3.51 \pm 1.24 p<0.001)$ and Visual Analogue Scale ( $-8.42 \pm 3.86$ vs. $2.1 \pm 5.11 p<$ $0.005)$ as craving scores. In addition, the acute administration of OT significantly reduced the withdrawal symptom as measured by Clinical Opioid Withdrawal Scale $(-10.45 \pm 2.99$ vs. $2.45 \pm 2.71 p<0.001)$. However, OT therapy did not significantly affect the mean differences of the anxiety scores compared with the placebo group $(-9.12 \pm 1.89$ vs. $-6.39 \pm 1.05 p<0.11)$. 
Table 1. General characteristics of the study participants

\begin{tabular}{lccc}
\hline Character & $\begin{array}{l}\text { Oxytocin group } \\
(n=29)\end{array}$ & $\begin{array}{l}\text { Placebo group } \\
(n=29)\end{array}$ & $p$ value \\
\hline Age, years & $32.81 \pm 8.6$ & $33.58 \pm 9.1$ & 0.759 \\
Marital status, $n$ (\%) & $12(44.4)$ & $7(29.2)$ & \\
$\quad$ Permanent marriage & $12(44.4)$ & $13(54.2)$ & 0.678 \\
Single/never married & $1(3.7)$ & $2(8.3)$ & \\
Separated/but not divorce & $2(7.4)$ & $2(8.3)$ & \\
Divorced & $3(11.1)$ & $2(8.3)$ & \\
Educational status, $n(\%)$ & $5(18.1)$ & $9(4.2)$ & \\
Illiterate & $7(25.9)$ & $9(37.5)$ & \\
Elementary & $9(33.3)$ & $1(4.2)$ & \\
Primary & $3(11.1)$ & $2(8.3)$ & \\
High school & $0(0)$ & \\
College & & \\
BSc &
\end{tabular}

Data are means \pm SD obtained from chi-square test and Mann-Whitney and $t$ test.

Table 2. Means \pm SD of craving scores; DDQ and VAS, COWS, and anxiety at baseline and after the oxytocin therapy in heroin-dependent patients. $p$ values show the differences between after and before the study in each group and result from the paired $t$ test

\begin{tabular}{llllll}
\hline Variables & Groups & $\begin{array}{l}\text { Before } \\
\text { intervention, } \\
\text { mean } \pm \text { SD }\end{array}$ & $\begin{array}{l}\text { After } \\
\text { intervention, } \\
\text { mean } \pm \text { SD }\end{array}$ & $\begin{array}{l}\text { Mean } \\
\text { differences, } \\
\text { mean } \pm \text { SD }\end{array}$ & $p$ value \\
\hline DDQ & Placebo & $38.18 \pm 3.12$ & $41.69 \pm 2.88$ & $3.51 \pm 1.24$ & 0.001 \\
& Oxytocin & $35.95 \pm 5.33$ & $18.79 \pm 3.08$ & $-17.16 \pm 4.36$ & $2.1 \pm 5.11$ \\
\hline VAS & Placebo & $32.25 \pm 3.69$ & $34.35 \pm 5.09$ & 0.005 \\
& Oxytocin & $32.50 \pm 5.75$ & $24.08 \pm 5.38$ & $-8.42 \pm 3.86$ & 0.001 \\
\hline Anxiety & Placebo & $28.04 \pm 2.46$ & $30.59 \pm 3.18$ & $2.45 \pm 2.71$ & 0.11 \\
& Oxytocin & $29.83 \pm 4.61$ & $19.37 \pm 4.26$ & $-10.45 \pm 2.99$ & \\
\hline
\end{tabular}

DDQ, Desire for Drug Questionnaire; VAS, Visual Analog Scale; COWS, Clinical Opioid Withdrawal Scale.

\section{The Effects of OT on Stress-Related Hormones}

The assessment of the serum cortisol level in the baseline did not show any significant difference between the control and the OT groups $(20.28 \pm 1.34 \mathrm{vs} .19 .81 \pm 2.38 \mu \mathrm{g} / \mathrm{dL})$. The cortisol levels at 30 and $60 \mathrm{~min}$ after the stress test were $21.21 \pm 1.51$ and $22.34 \pm 1.40$ in the control group and $16.14 \pm 1.57$ and $15.21 \pm 2.22$ in the OT treatment group (Fig. 2). These results demonstrated that in comparison with the placebo group, the OT treatment significantly decreased serum cortisol level ( $p$ value $<0.01$ ). The baseline
DHEASlevels were $311.15 \pm 12.69$ and $312.69 \pm 10.33$ in the control and the OT group respectively. The DHEAS levels in 30 and $60 \mathrm{~min}$ after the stress test were $306.46 \pm 10.45 \mathrm{vs.}$ $314.47 \pm 9.52$ and $308.22 \pm 11.06$ vs. $317.53 \pm 10.63$ (Fig. 3 ). Results showed that there were no significant differences in DHEAS levels between the control and the treatment groups ( $p$ value $=0.133$ ). However, as shown in Figure 4, the Cortisol/DHEAS ratio at $60 \mathrm{~min}$ after the stress test showed a significant difference ( $p$ value $<0.05$ ) between the placebo $(6.89 \pm 0.84)$ and the OT groups (4.28 \pm 0.81 ; Fig. 4). 


\section{Discussion}

To our knowledge, the present study is the first randomized, double-blind placebo-controlled clinical trial on the effects of OT on withdrawal, craving and stress response in heroin-dependent patients. In this research, intranasal administration of OT (single dose; $40 \mathrm{IU}$ ) improved withdrawal symptoms, craving, cortisol level and cortisol/DHEAS ratio in the therapeutic group.

Numerous preclinical researches on the effects of OT on opioid-related behaviour have been done. Peripheral administration of OT has been shown to inhibit the development of the tolerance and withdrawal to opioids. This effect seems to be centrally mediated $([7,26]$ for review). The mechanisms by which the OT changes the behavioural response to opioids are about to be understood. It has been shown that chronic morphine treatment inhibits OT synthesis in rats with a decrease in the supraoptic nucleus and nucleus accumbens and an increase in the ventral tegmentum area and locus ceroleus [27]. Also, repeated morphine administration has enhanced the OT receptor binding in the olfactory nuclei, piriform cortex, septum and amygdala, while it has decreased the OT peptide level in the hypothalamus. Administration of exogenous OT may reverse these changes in OT synthesis and receptors and this might translate to reversal of addictive behaviour [28].

Recent studies indicate that social attachments protect against addiction and health consequences of stress, whereas drug abuse and chronic stress can undermine social attachment $[29,30]$. Indeed, negative social experiences generally increase the vulnerability to drug abuse, while the development of strong social attachments, including parent-offspring and adult pair bonding may buffer substance abuse [31]. It is suggested that OT increases resilience against addiction and stress through the interaction with the central dopaminergic, serotonergic and the endogenous opioid system. This is done by facilitating the process of social bonding and attachmentrelated information and its consolidation in internal working models. Thus, it contributes to promoting a shift from novelty seeking towards preference of social familiarity through the cortical route [32]. The increasing body of evidence shows that stress exposure is an important contributing factor to drug dependence and suggests that cortisol release induced by stress of withdrawal, increases drug reinforcement. Our clinical data suggest that the OT may be useful to reduce craving and withdrawal symptoms through its effects on the HPA axis and attenuating stress-related physiological and subjective response [16].

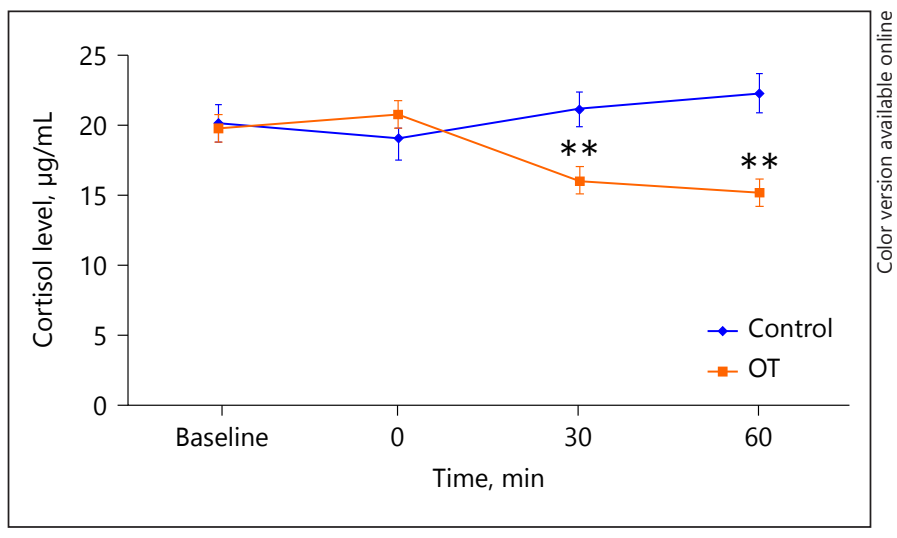

Fig. 2. The serum cortisol level $(\mu \mathrm{g} / \mathrm{dL})$ in the baseline and after cue-induced craving task ( $\mathrm{min}$ ) in control and OT groups. The results are expressed as mean \pm SEM. ${ }^{* *} p<0.01$ versus control group. OT, oxytocin.

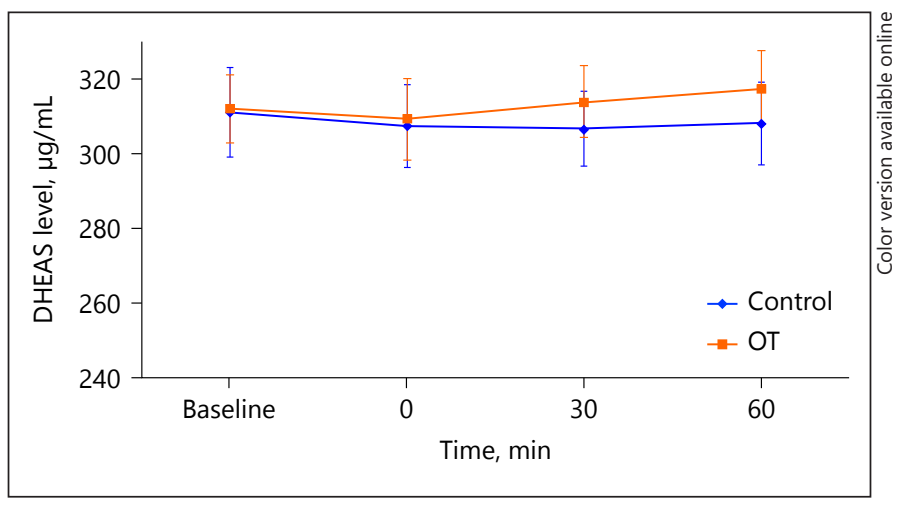

Fig. 3. The serum DHEAS level $(\mu \mathrm{g} / \mathrm{dL})$ in the baseline and after cue-induced craving task ( $\mathrm{min}$ ) in control and OT groups. Results are expressed as mean \pm SEM. DHEAS, dehydroepiandrosterone sulfate; OT, oxytocin.

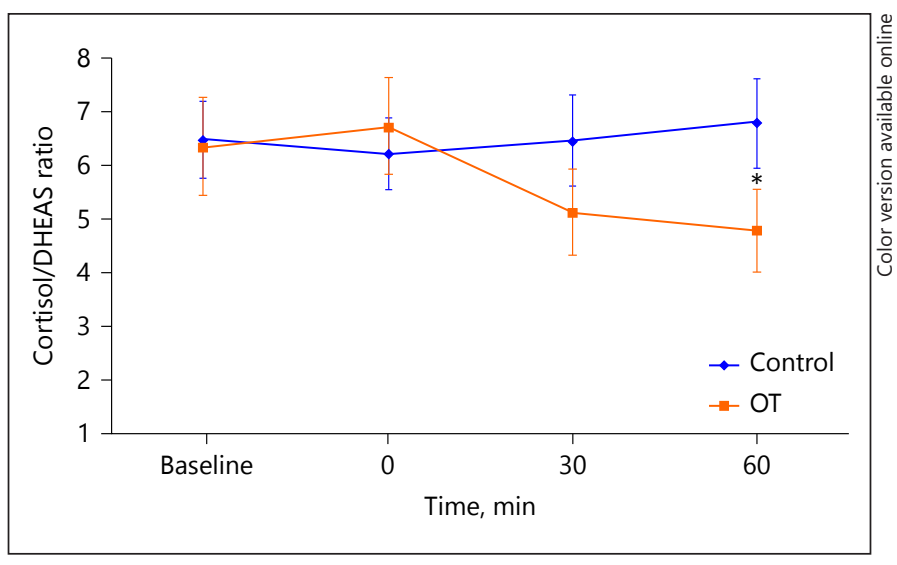

Fig. 4. The cortisol/DHEAS ratio $(* 100)$ in the baseline and after cue-induced craving task ( $\mathrm{min}$ ) in control and OT groups. Results are expressed as mean \pm SEM. DHEAS, dehydroepiandrosterone sulfate; OT, oxytocin. 
Our results indicate that OT does not affect subjective self-reporting of anxiety. Lack of effect on subjective stress may be attributable to inefficient OT's dose or to the method used to assess stress (i.e., reliance on a blood venipuncture instead of salivary sample).

The present data demonstrates that intranasal OT decreased the serum cortisol level and improved the cortisol/ DHEAS ratio, which has been proved to be a reliable predictor for health and stress. These findings are in agreement with the previous finding. It has been shown that intranasal OT significantly increased positive communication behaviour and reduced salivary cortisol levels during the couple conflict discussion compared with the placebo [33]. It has also been shown that exogenous OT administration has a boosting effect on the baseline activity of the brain OT system by raising brain OT levels [34, 35]. OT has been suggested to reduce HPA axis activation during the stress. It has been shown that the activation of the OT receptor in the paraventricular nucleus delays the transcription of the gene-encoding corticotropin-releasing factor, which is the main regulator of the stress response [36]. Molecular studies have shown localized OT receptors in the mesolimbic dopamine reward circuit, including the amygdala, the nucleus accumbens, the ventral tegmental area, and the corticotrophin-releasing factor stress systems [37]. OT and DHEAS are thought to influence central dopamine release considering the fact that the dopamine plays a major role in drug-induced reward. It is possible that OT administration also reduces craving and withdrawal-induced stress through interaction with the mesocorticolimbic dopaminergic system and other neurotransmitter systems involved in addiction [38]. It is a fact that OT itself does not have rewarding effects and makes it a potential adjunct treatment for heroin addiction [39].

Our study showed that intranasal OT reduced craving and withdrawal scores but did not change anxiety signifi- cantly in the heroin users during the abstinence. Also, the positive effects of OT on stress-related hormones may be involved in this effect of OT. Overall, this study suggest that OT may play a role in the attenuation of craving, withdrawal symptom in heroin-dependent patients, and can be considered a new potential treatment for heroin addiction.

\section{Limitation}

The relatively small number of the subjects enrolled in this study requires that our results be considered preliminary. Future studies of considerably larger sample size will be necessary to adequately test the validity of our findings. The long-term intervention might lead to better effects of OT. Finally, all participants were male and the current results need to be replicated in female groups.

\section{Acknowledgements}

The present study was supported by a grant from the Vicechancellor for Research of KUMS in Iran. The authors would like to thank the Welfare of Isfahan Province for their assistance in this project.

\section{Ethics Statement}

This randomized, double-blind placebo-controlled clinical trials was registered in the Iranian website for registration of clinical trials as http://www.irct.ir: IRCT (2015103024792N1). This research was carried out in accordance with the Declaration of Helsinki and received approval from the Ethics Committee of Kashan University of Medical Sciences (KAUMS).

\section{Disclosure Statement}

The authors declare that there are no conflicts of interests regarding the publication of this paper.

\section{References}

1 United Nations: Office of Drug and Crime: World Drug Report 2018 (United Nations publication, Sales No. E.18.XI.9).

2 Yen CF, Lin HC, Wang PW, Ko CH, Lee KH, Hsu CY, Chung KS, Wu HC, Cheng CP: Heroin craving and its correlations with clinical outcome indicators in people with heroin dependence receiving methadone maintenance treatment. Compr Psychiatry 2016;65: 50-56.

3 Colom Farran J, Casas M, Pérez de Los Cobos J, Del Río M, Roncero C, Castells X, Valero S, Eiroa-Orosa FJ, Batlle F, Trujols J: Feasibility of double-blind clinical trials with oral diacetylmorphine: a randomized controlled phase II study in an inpatient setting. Eur Addict Res 2012;18:279-287.

4 Krantz MJ, Rowan SB, Schmittner J, Bucher Bartelson B: Physician awareness of the cardiac effects of methadone: results of a national survey. J Addict Dis 2007;26:79-85.

5 Singh F, Nunag J, Muldoon G, Cadenhead KS, Pineda JA, Feifel D: Effects of intranasal oxytocin on neural processing within a socially relevant neural circuit. Eur Neuropsychopharmacol 2016;26:626-630.
6 Amini-Khoei H, Amiri S, Mohammadi-Asl A, Alijanpour S, Poursaman S, HajMirzaian A, Rastegar M, Mesdaghinia A, Banafshe HR, Sadeghi E, Samiei E, Mehr SE, Dehpour AR: Experiencing neonatal maternal separation increased pain sensitivity in adult male mice: involvement of oxytocinergic system. Neuropeptides 2017;61: 77-85.

7 Lee MR, Rohn MC, Tanda G, Leggio L: Targeting the oxytocin system to treat addictive disorders: rationale and progress to date. CNS Drugs 2016;30:109-123. 
8 Kovács GL, Sarnyai Z, Szabó G, Telegdy G: Development of morphine tolerance under tonic control of brain oxytocin. Drug Alcohol Depend 1986;17:369-375.

9 McRae-Clark AL, Baker NL, Maria MM, Brady KT: Effect of oxytocin on craving and stress response in marijuana-dependent individuals: a pilot study. Psychopharmacology (Berl) 2013;228:623-631.

10 Lin SH, Lee LT, Tsai HC, Chen KC, Chen WT, Lee IH, Lu RB, Chen PS, Yang YK: Association between blood level of plasma oxytocin and novelty seeking among methadonemaintained heroin users. Neuropsychobiology 2015;71:65-69.

11 Light KC, Grewen KM, Amico JA, Boccia M, Brownley KA, Johns JM: Deficits in plasma oxytocin responses and increased negative affect, stress, and blood pressure in mothers with cocaine exposure during pregnancy. Addict Behav 2004;29:1541-1564.

12 Walter M, Bentz D, Schicktanz N, Milnik A, Aerni A, Gerhards C, Schwegler K, Vogel M, Blum J, Schmid O, Roozendaal B, Lang UE, Borgwardt S, de Quervain D: Effects of cortisol administration on craving in heroin addicts. Transl Psychiatry 2015;5:e610.

13 Schmidt A, Borgwardt S, Gerber H, Wiesbeck GA, Schmid O, Riecher-Rössler A, Smieskova R, Lang UE, Walter M: Acute effects of heroin on negative emotional processing: relation of amygdala activity and stress-related responses. Biol Psychiatry 2014;76:289-296.

14 Olff M, de Vries GJ, Güzelcan Y, Assies J, Gersons BP: Changes in cortisol and DHEA plasma levels after psychotherapy for PTSD. Psychoneuroendocrinology 2007;32:619-626.

15 Rasmusson AM, Vasek J, Lipschitz DS, Vojvoda D, Mustone ME, Shi Q, Gudmundsen G, Morgan CA, Wolfe J, Charney DS: An increased capacity for adrenal DHEA release is associated with decreased avoidance and negative mood symptoms in women with PTSD Neuropsychopharmacology 2004;29:15461557.

16 Lee MR, Weerts EM: Oxytocin for the treatment of drug and alcohol use disorders. Behav Pharmacol 2016;27:640-648.

17 Ghaderi A, Banafshe HR, Motmaen M, Rasouli-Azad M, Bahmani F, Asemi Z: Clinical trial of the effects of vitamin D supplementation on psychological symptoms and metabolic profiles in maintenance methadone treatment patients. Prog Neuropsychopharmacol Biol Psychiatry 2017;79(pt B):84-89.
18 Wesson DR, Ling W: The clinical opiate withdrawal scale (COWS). J Psychoactive Drugs 2003;35:253-259.

19 Wewers ME, Lowe NK: A critical review of visual analogue scales in the measurement of clinical phenomena. Res Nurs Health 1990; 13:227-236.

20 Franken IH, Hendriksa VM, van den Brink $\mathrm{W}$ : Initial validation of two opiate craving questionnaires the obsessive compulsive drug use scale and the desires for drug questionnaire. Addict Behav 2002;27:675-685.

21 Hamilton M: The assessment of anxiety states by rating. Br J Med Psychol 1959;32:50-55.

22 Ditzen B, Schaer M, Gabriel B, Bodenmann G, Ehlert U, Heinrichs M: Intranasal oxytocin increases positive communication and reduces cortisol levels during couple conflict. Biol Psychiatry 2009;65:728-731.

23 Heinrichs M, Baumgartner T, Kirschbaum C, Ehlert U: Social support and oxytocin interact to suppress cortisol and subjective responses to psychosocial stress. Biol Psychiatry 2003; 54:1389-1398.

24 Ekhtiari H, Edalati H, Behzadi A, Safaea H, Noori M, Mokri A: Construction and evaluation of the effectiveness of five visual tests of assessment of substance craving in addicts, Iran. J Psychiatry Clin Psycho 2008;14:337349.

$25 \mathrm{Yu}$ J, Zhang S, Epstein DH, Fang Y, Shi J, Qin $\mathrm{H}$, Yao S, Le Foll B, Lu L: Gender and stimulus difference in cue-induced responses in abstinent heroin users. Pharmacol Biochem Behav 2007;86:485-492.

26 Kovács GL, Sarnyai Z, Szabó G: Oxytocin and addiction: a review. Psychoneuroendocrinology 1998;23:945-962.

27 You ZD, Li JH, Song CY, Wang CH, Lu CL: Chronic morphine treatment inhibits oxytocin synthesis in rats. Neuroreport 2000;11: 3113-3116.

28 Zanos P, Georgiou P, Wright SR, Hourani SM, Kitchen I, Winsky-Sommerer R, Bailey A: The oxytocin analogue carbetocin prevents emotional impairment and stress-induced reinstatement of opioid-seeking in morphineabstinent mice. Neuropsychopharmacology 2014;39:855-865.

29 Buisman-Pijlman FT, Sumracki NM, Gordon JJ, Hull PR, Carter CS, Tops M: Individual differences underlying susceptibility to addiction: role for the endogenous oxytocin system. Pharmacol Biochem Behav 2014;119: 22-38.
30 Liu Y, Young KA, Curtis JT, Aragona BJ, Wang Z: Social bonding decreases the rewarding properties of amphetamine through a dopamine D1 receptor-mediated mechanism. J Neurosci 2011;31:7960-7966.

31 Young LJ, Rainnie DG, et al: Neuroanatomical evidence for reciprocal regulation of the corticotrophin-releasing factor and oxytocin systems in the hypothalamus and the bed nucleus of the stria terminalis of the rat: implications for balancing stress and affect. Psychoneuroendocrinology 2011;36:13121326.

32 Tops M, Koole SL, IJzerman H, Buisman-Pijlman FT: Why social attachment and oxytocin protect against addiction and stress: insights from the dynamics between ventral and dorsal corticostriatal systems. Pharmacol Biochem Behav 2014;119:39-48.

33 Ditzen B, Schaer M, Gabriel B, Bodenmann G, Ehlert U, Heinrichs M: Intranasal oxytocin increases positive communication and reduces cortisol levels during couple conflict. Biol Psychiatry 2009;65:728-731.

34 Burkett JP, Young LJ: The behavioral, anatomical and pharmacological parallels between social attachment, love and addiction. Psychopharmacology (Berl) 2012;224:1-26.

35 Di Simplicio M, Massey-Chase R, Cowen PJ, Harmer CJ: Oxytocin enhances processing of positive versus negative emotional information in healthy male volunteers. J Psychopharmacol 2009;23:241-248.

36 Jurek B, Slattery DA, Hiraoka Y, Liu Y, Nishimori K, Aguilera G, Neumann ID, van den Burg EH: Oxytocin regulates stress-induced Crf gene transcription through CREB-regulated transcription coactivator 3 . J Neurosci 2015;35:12248-12260.

37 Vaccari C, Lolait SJ, Ostrowski NL: Comparative distribution of vasopressin V1b and oxytocin receptor messenger ribonucleic acids in brain. Endocrinology 1998;139:5015-5033.

38 Baracz SJ, Everett NA, McGregor IS, Cornish $\mathrm{JL}$ : Oxytocin in the nucleus accumbens core reduces reinstatement of methamphetamineseeking behaviour in rats. Addict Biol 2016; 21:316-325.

39 Qi J, Yang JY, Wang F, Zhao YN, Song M, Wu CF: Effects of oxytocin on methamphetamine-induced conditioned place preference and the possible role of glutamatergic neurotransmission in the medial prefrontal cortex of mice in reinstatement. Neuropharmacology 2009;56:856-865. 